Mots. Les langages du politique

\title{
Cicéron contre Antoine : la désignation de l'ennemi dans la guerre civile
}

Cicero versus Anthony: naming the enemy in civil wars

Cicero contra Antonio: como llamar al enemigo en la guerra civil

\section{Ninon Grangé}

\section{CpenEdition}

Journals

Édition électronique

URL : https://journals.openedition.org/mots/15512

DOI : $10.4000 /$ mots. 15512

ISSN : 1960-6001

Éditeur

ENS Éditions

Édition imprimée

Date de publication : 1 novembre 2003

Pagination : $9-23$

ISBN : 2-84788-043-7

ISSN : 0243-6450

\section{Référence électronique}

Ninon Grangé, «Cicéron contre Antoine : la désignation de l'ennemi dans la guerre civile », Mots. Les

langages du politique [En ligne], 73 | 2003, mis en ligne le 09 octobre 2008, consulté le 22 avril 2022

URL : http://journals.openedition.org/mots/15512 ; DOI : https://doi.org/10.4000/mots.15512

\section{(C) ENS Éditions}


Ninon GRANGÉ ${ }^{1}$

\section{Cicéron contre Antoine : la désignation de l'ennemi dans la guerre civile}

Pourquoi Cicéron, alors qu'il réfléchit à la guerre, évite-t-il de parler de guerre civile? Dans les traités philosophiques, Laelius sive de amicitia, De officiis, le bellum civile ("guerre civile ») n'existe pas ; seule est développée l'idée de guerre pour la gloire ou la conservation tandis que les allusions à Sylla ou César ne sont pas théorisées. La notion est discrète dans les Philippiques, écrites au même moment (44-43 av. J.-C.), qui relate pourtant la sécession d'Antoine et de ses légions ${ }^{2}$. La République est divisée entre ses généraux, entre les fidèles à la mémoire de César comme Antoine et ceux qui, tel Cicéron, ne regrettent pas celui qui a voulu restaurer la monarchie, entre les tenants de l'autorité du Sénat et ceux de la puissance des armées.

On privilégiera, par rapport aux épisodes de Catilina (-63) ou de Milon et Clodius (-52), l'affrontement entre Antoine et Cicéron $(-44-43)$ pour montrer comment la rhétorique se fait pensée politique au plus fort du danger de mort pour la République, et déplace la menace réelle vers le concept d'ennemi intérieur afin d'éviter de nommer la guerre civile. Pourquoi Cicéron, érudit en lettres grecques et admirateur de Platon, ne transpose-t-il pas la notion de $\operatorname{stasis}^{3}$, station et révolution à la fois, scission de la cité ? Le mal absolu est-il si peu dicible que son lieu n'est pas un traité sur la justice? Il se développe alors en creux dans les Philippiques.

1. ENS-LSH - 15, Parvis René-Descartes 69366 Lyon cedex 07 - ninon.grange@ libertysurf.fr

2. Voir De officiis, I, XII, 37-38, édition utilisée : Cicéron, Les devoirs, trad. M. Testard, Paris, les Belles Lettres, 1974. La comparaison entre vie civile et vie militaire : I, XXII, 74-XXV, 89 et II, VIII, 28-29. Pour les Philippiques, édition utilisée : Cicéron, Philippiques, trad. A. Boulanger et P. Wuilleumier, Paris, les Belles Lettres, 1959 ; Cicéron, Catilinaires, trad. M. Magnien, Paris, Le Livre de Poche, 1992 ; pour le Laelius sive de amicitia, Cicéron, L'amitié, trad. R. Combès, Paris, les Belles Lettres, 2001.

3. Voir N. Loraux, 1997, La cité divisée, Paris, Payot. 
On analysera donc les caractérisations d'Antoine - figure de l'ennemi et non personnage historique - qui assument les contenus assignables à la guerre civile, pour la conjurer.

\section{Hostis et hostis publicus}

La réflexion de Cicéron s'organise autour d'une distinction très latine entre l'inimicus, l'ennemi privé, et l'hostis, à l'origine l'étranger puis l'ennemi d'un groupe, qui est généralement l'entité politique Rome. L'hostis publicus («ennemi public», publicus est souvent sous-entendu) désigne aussi bien les ennemis étrangers de Rome, que l'ennemi intérieur qui transgresse la loi de la communauté politique : le référent stable est Rome attaquée d'où se déduit l'attaquant ${ }^{4}$. Cicéron investit l'expression de plusieurs valeurs qui rejaillissent implicitement sur le concept variable de bellum, dont le référent n'est plus, comme dans le De officiis, la guerre menée selon la justice.

Les affaires Catilina ou Clodius se situaient en amont du conflit civil ; les deux hommes sont qualifiés le plus souvent chacun d'inimicus, voire de criminel coupable d'un délit (facinus), alors que se dessine le grand danger que court la République. L'ennemi est « dans nos murs et, bien plus, au Sénat » (In Catilinam I, II, 5), il est à l'intérieur, parmi nous, indiscernable du reste des citoyens: «Hic, hic sunt, in nostro numero » («c'est ici, parmi nous, qu'ils sont», Cat. I, IV, 9). La caractérisation de l'ennemi introduit donc directement au type d'état de guerre «horrible et néfaste " ("horribile ac nefarium bellum », Cat. II, VII, 15). Horrible renvoie à l'histoire connue, néfaste à ce qu'il y a à craindre de l'avenir.

Dans cette tradition et spécialement chez Cicéron, l'hostis publicus procède de la volonté d'installer tout fauteur de troubles à l'extérieur de Rome pour exercer contre lui le droit de la guerre, ce qui est par définition impossible dans le cas d'un citoyen romain. C'est à cette contradiction que Cicéron se trouve confronté de manière pressante. Synonyme de l'expression hostis rei publicae («ennemi de la république »), hostis publicus indique la destination de la violence - contre le peuple - mais aussi la provenance, puisque l'ennemi intérieur est issu du peuple, de l'assemblée des citoyens. Avec les Philippiques, Cicéron tente de sortir de cette scission en maintenant la ten-

4. Voir J. Hellegouarc'h, 1963, Le vocabulaire latin des relations et des partis politiques sous la république, Paris, les Belles Lettres, et Éditions Teubner, 1936-1942, Thesaurus linguae latinae, vol. VI, p. 3055-3066. 
sion entre confrontation belliqueuse et conflit interne; au lieu de civile, la guerre sera un "bellum intestinum et domesticum» ("guerre intestine et domestique », Cat. II, XIII, 48), «malum civile ac domesticum» (« mal civil et domestique », Cat. IV, VII, 15). Comme l'évitement de l'expression implique que nommer, c'est faire exister, Cicéron conjure la guerre civile en déplaçant le centre de gravité de la violence depuis l'entité politique abstraite Rome vers l'individu nouvellement ennemi. Aussi les Philippiques, dans l'urgence et l'action immédiate, dénoncent-elles un homme et un état de guerre inédit, vierge de déterminations, par rapport au De officiis où l'absence de mention de la guerre civile est une thèse en soi. La conversion d'Antoine d'ami politique en ennemi a pour conséquence l'invention de dispositifs de désignation désamorçant la portée néfaste de la discorde.

La notion d'ennemi intérieur est en toute logique un non-sens - comment un citoyen peut-il prendre les armes contre ses concitoyens, comment une unité politiquement organisée peut-elle se déclarer la guerre à elle-même ? Cicéron, devant le vide conceptuel et le défaut lexical, va investir la figure de l'ennemi Antoine d'une valeur négative puisque celui-ci n'en a pas d'emblée, à la différence des ennemis extérieurs et historiques, Gaulois, Germains, Barbares... Pour éviter le paradoxe de la cité en guerre contre ellemême, Cicéron se donne une tâche quasi impossible: convertir la guerre civile en guerre étrangère fictive menée par Rome et faire d'Antoine un hostis sans pour autant le reconnaitre comme belligérant.

La variété des qualificatifs attribués à Antoine donne un nouveau sens, plus complet, au terme d'hostis, en fonction de la figure et des agissements d'Antoine.

Antoine a l'initiative de ce curieux État où la République est immédiatement en danger de mort car la défection de l'un de ses membres équivaut à la scission politique de la communauté divisée de fait. « Nous tous [...] il nous a désignés, non comme des adversaires, mais comme des ennemis » (« statuit ille quidem non inimicos, sed hostis ${ }^{5} »$, Phil. XI, I, 3). Ce n'est pas pour varier le style que Cicéron emploie les deux termes. Il ne se livre pas à une criminalisation d'Antoine, il met en évidence la menace en imbriquant volontairement, sans ordre hiérarchique, les exemples d'exactions multiples. Alors que rien n'est permis pour une guerre civile - c'est ce qu'on déduit de son absence du De officiis et de la définition de la guerre juste ${ }^{6}-$ Antoine se permet tout. Il trahit ses ancêtres, ses héritages, ses concitoyens, jusqu'à la

5. Je maintiens l'orthographe d'origine, soit -is pour -es au nominatif et à l'accusatif masculins pluriels.

6. Voir Cicéron, De republica, II, 31 et III, 37 ; Off., I, 36. 
mémoire de César dont il se dit le dépositaire. Il renie à la fois ses origines et son appartenance politique. Pêle-mêle, Cicéron évoque l'enrichissement illégal, le vol du Trésor dans le temple d'Ops, les intimidations, les violences envers les citoyens et le Sénat. Antoine non seulement dénoue les liens de l'amitié politique (il lit publiquement une lettre privée), mais manque aux devoirs familiaux et religieux ; il transgresse ainsi les devoirs de réciprocité et de bonne foi ${ }^{7}$. Cicéron lui déclare d'abord une guerre personnelle : comme pour Catilina, il "prend sur [lui] la haine des scélérats » (Cat. II, V, 11); mais rapidement la guerre interindividuelle devient collective. Le discours de Cicéron contre Antoine au Sénat transforme les inimici en hostes en passant par les « citoyens impies » (Phil. II, I, 1). Pour assurer cette transformation, Cicéron mêle le particulier et le général en relatant les exactions commises : Antoine a trahi son ami Clodius, il mène l'expédition d'Alexandrie «contre l'autorité du Sénat, contre l'intérêt public et les interdictions religieuses », il pille jardins et maisons, trouble les obsèques de César et investit le Sénat et le temple de la concorde d'hommes en armes. La convertibilité ami-ennemi est vérifiée : Antoine est inimicus de plusieurs citoyens et hostis de la République. Cicéron, représentant l'une et les autres ${ }^{8}$, entend séparer les cives boni ( « bons citoyens ») et les impii cives (« citoyens impies »), en entrelaçant les déterminations des concepts en amont de celui, effrayant, de guerre civile. En ce sens la guerre civile est une guerre extraordinaire?

La caractérisation d'Antoine comme traitre, déloyal et débauché permet la construction d'un type d'ennemi qu'il est impératif de toujours requalifier négativement, tant la menace qu'il représente par sa seule personne insurgée est grande. Rome risque le mal politique, la servitude volontaire ${ }^{10}$, preuve que la cité divisée est en proie à une contradiction suicidaire ; elle est menacée « de fond en comble » (Laelius, VII, 23). La figure d'Antoine rejoint celles de Catilina, Clodius et Spartacus pour démembrer les parties constitutives de Rome. Dans la situation extrême de séparation de la communauté, la République ne peut plus aménager les dispositifs de la raison d'État pour se porter secours à elle-même.

Contrairement à ce qui s'était passé avec Catilina, Cicéron échoue à transformer la situation en conflit de personnes. Il se tourne alors vers une solution hyper-légale, qui ne se confond pas avec des mesures d'exception : le contenu de l'hostis publicus variera en fonction des déterminations supposées de

7. Phil. II, IV, 7 et Epistulae ad Atticum, XIV, 13.

8. Voir Phil. I, I, 1.

9. Phil. II, XIX, 48 ; Phil. III, XII, 30 ; voir Phil. II, IX, 23-24.

10. Phil. I, VI, 15. 
la guerre civile, sans installer officiellement l'état de guerre. La désignation d'hostis devient plus complexe, contaminée par la personnalité d'Antoine, citoyen romain.

\section{La tension entre ennemi intérieur et ennemi extérieur}

Cicéron veut exclure Antoine de l'ensemble des citoyens afin que la scission interne soit désamorcée, mais il ne peut le rendre totalement extérieur. Aussi entend-il montrer que c'est Antoine qui s'est lui-même désigné ennemi. Le risque de dédoublement de l'unité politique en est réduit. Cicéron renouvelle ainsi le sens de publicus, le plus souvent de manière implicite, en jouant sur l'opposition entre l'orateur et le général, entre le traitre et sa patrie, entre les deux généraux Antoine et Octave.

En n'osant déférer au Sénat le cas d'un homme [Octave] qui s'est mis à la tête d'une armée dirigée contre lui, consul, faisait-il autre chose que se déclarer luimême ennemi public? Il fallait forcément que l'un ou l'autre fût ennemi public, et il n'était pas possible de décider autrement entre deux généraux opposés l'un à l'autre (Phil. III, VII, 21) ${ }^{11}$.

L'autodésignation contre le pouvoir est un principe général de toute insurrection; en l'occurrence la transgression politique est renforcée par le fait qu'Antoine est consul. À Antoine, Cicéron oppose sa propre personne, consulaire et sénateur, et Octave, général prometteur en Orient. On a vu qu'Antoine défaisait les liens de l'amitié et de l'amitié politique; il est également illégitime devant ses armées. À la différence de ses légions qui ont au préalable prêté serment à leur chef, Antoine est un délieur de serment, un parangon de la mauvaise foi en une opposition directe au De officiis, où la fides («bonne foi ») est un principe. Il est un citoyen non seulement mauvais mais radicalement contraire. En dédouanant les légions d'Antoine, Cicéron déplace la contradiction inhérente à toute guerre civile vers la personne du général contraire à Rome, à l'armée, au peuple. Il rabat le paradoxe sur la figure de l'ennemi. C'est pourquoi il fait de la volonté d'Antoine la contradiction de son origine romaine. Le terme de volonté a ceci d'intéressant qu'il n'a aucune détermination morale dans les Philippiques, mais bien une fonction qui en fait l'opposé de la nature. Employé à l'ablatif comme complément du terme ennemi, il peut être mis en parallèle avec la formule, marque de la

11. "Quid est aliud de eo referre non audere qui contra se consulem exercitum duceret, nisi se ipsum hostem iudicare? Necesse erat enim alterutrum esse hostem, nec poterat aliter de adversariis iudicari ducibus ». 
légalité, de iure. Quand tout citoyen et l'entité politique Rome agissent de iure, Antoine agit voluntate:

Et tu dis que tu as été porté à toujours souhaiter la paix, à toujours désirer le salut de tous les citoyens. Langage honorable mais à condition qu'il vise les citoyens bons, utiles et dévoués à la République; si tu désires le salut de ceux que la nature a faits citoyens et que la volonté a rendus ennemis [natura cives sunt, voluntate hostes], quelle différence y aurait-il enfin entre toi et eux (Phil. VIII, IV, 13) ${ }^{12}$ ?

La naissance, dont participe aussi le bellum régulier, est affaire de nature, le vice et la trahison procèdent exclusivement de la volonté. L'État est une seconde nature ${ }^{13}$, il n'est pas l'expression d'une volonté générale. Antoine est aux antipodes de la volonté bonne, conforme à la natura, et qui se traduit par la formule convenable du rapport entre les hommes, dont les deux principes sont l'hospitalité et la guerre juste: "voluntate hospitem, necessitate hostem » (« hôte par volonté, ennemi par nécessité », Phil. XII, XI, 27), c'est la leçon du De officiis qui se retrouve dans les Philippiques. Dans la démonstration conséquente de Cicéron, Antoine est dégénéré, il a une volonté corrompue, de sorte que «c'est une guerre sacrilège qu'[il] a entreprise contre [sa] patrie» (« bellum contra patriam nefarium»), qui s'apparente à une «défection au peuple romain » (Phil. XIII, XVIII, 39) ${ }^{14}$.

Cicéron ne veut pas nommer la guerre ainsi instaurée mais il ne peut reconnaitre Antoine comme simple hostis, au même titre qu'un ennemi régulier. La solution hyper-légale consiste donc à réitérer la désignation de l'ennemi pour le compte de Rome. Pour tenter de résoudre la tension entre ennemi intérieur et ennemi extérieur, Cicéron se tourne, provisoirement, vers la solution d'une décision solennelle.

Pour maitriser les évènements, tout en laissant à Antoine la responsabilité du chaos, il faut que le Sénat et le peuple le proclament ennemi de manière solennelle : la Quatrième Philippique est justement prononcée devant le peuple dont Cicéron veut obtenir l'adhésion pour obliger le Sénat à cette proclamation. C'est une autre manière de conjurer la guerre civile que de rechercher l'unanimité du peuple en supprimant du même coup la notion de discorde. De manière quasi performative, Cicéron recrée l'unité de Rome en créant l'unité

12. " Atque ais eum te esse qui semper pacem optaris, semper omnis civis volueris salvos. Honesta oratio, sed ita, si bonos et utilis et e re publica civis; sin eos qui natura cives sunt, voluntate hostes, salvos velis, quid tandem intersit inter te et illos?"

13. Voir De legibus, II, II, 5 et la théorie des deux patries.

14. Voir aussi Phil. XIII, XX, 47 ; Phil. V, XII, 32 ; Phil. VIII, II, 7 et III, 8. Trad. modifiée : « a populo Romano defectionem » était traduit par « rébellion contre le peuple romain ». 
de l'assemblée du peuple. Il tient pour acquise la désignation sénatoriale d'Antoine comme ennemi public. Une nouvelle définition de l'hostis est formulée à cette occasion, il est celui contre lequel on a pris légitimement les armes $^{15}$. La constitution d'Antoine en ennemi public emprunte des raccourcis logiques : l'éloge d'Octave est complété par l'acclamation du peuple et la décision du Sénat, de sorte que l'ordre logique - décision, acclamation - est inversé, le peuple acclame une décision qui n'a pas encore été prise. L'État entérine et légalise l'adhésion de l'assemblée du peuple. Avec l'officialisation, le Sénat est dit «iudicare hostem » («juger, déclarer ennemi ») ${ }^{16}$, on perd la notion de publicus. Cicéron investit la notion d'ennemi de valeurs nouvelles par oppositions et rejets successifs. L'acclamation a priori du peuple contrebalance l'acclamation d'Antoine par ses troupes, qui l'ont revêtu d'un imperium régulier. Restaurer l'unité du peuple revient à disqualifier l'acclamation d'Antoine par ses soldats. Un bénéfice double est tiré de cette stratégie oratoire : en faisant d'Antoine l'épicentre impie de la guerre, Cicéron ménage la possibilité aux soldats de lui faire défection. Il devient légitime et même sacré de porter les armes contre Antoine ${ }^{17}$.

La représentation du peuple par l'armée fonctionne à deux titres dans ce discours, elle assure que le système d'expression des citoyens par la civitas est toujours valable - Rome est défendue à l'intérieur comme à l'extérieur parce qu'elle est une entité à visée universaliste qui s'exporte et qui exporte en même temps sa citoyenneté - par ailleurs, elle répond au paradoxe de la guerre civile qui trouble autant l'intérieur des murs que l'extérieur. L'exaltation par Cicéron de la $4^{\mathrm{e}}$ Légion qui a abandonné Antoine prouve que Rome est encore défendue au-dehors; elle est mieux défendue dans ses parties qu'en son centre ${ }^{18}$.

On perçoit que la guerre est toujours beaucoup plus acceptable à l'extérieur qu'à l'intérieur, même quand elle met aux prises des Romains. C'est pourquoi, dans un mouvement remarquable, Cicéron va imposer une fiction de guerre étrangère pour mieux cerner l'hostis. La tension sur l'ennemi intérieur et extérieur se répercute sur la notion de guerre, écartelée entre plusieurs formulations.

La tension entre contradiction insoutenable de la guerre civile et aspiration à la fiction d'un état de guerre étrangère se révèle dans la figure d'Antoine

15. Phil. IV, I, 2 : « contra quem iure arma sumpta sunt ». Le parfait est performatif.

16. Voir Phil. IV, II, 5 ; Phil. IV, II, 5 et Phil. IV, III, 6-7 : «hostem esse Antonium iudicatum », « hostem illum et latronem et parricidam patriae ».

17. Phil. III, VI, 14.

18. Phil. XII, II, 7 et III, 8. 
qui concentre l'image contre nature du citoyen-ennemi de sa patrie, défait de son appartenance politique, et d'ennemi fictivement extérieur, mais déloyal et indigne. Dans les Philippiques, la guerre civile tend à être limitée dans son origine - la volonté individuelle d'un citoyen traitre et impie - mais non dans ses conséquences. Antoine dévoie l'idée de guerre extérieure en la portant au sein d'une seule entité politique. La difficulté que ne surmontera pas Cicéron est que, pour contrer les effets néfastes de la guerre civile, il faut aller dans le sens d'Antoine et accepter la fiction de la guerre extérieure. Il est évident qu'Antoine ne respecte pas les lois de la guerre, mais en faisant le siège de Modène, il fait semblant de mener une guerre étrangère alors qu'elle est fratricide. Les Philippiques ont un double effet : vis-à-vis du De officiis et visà-vis de la situation contemporaine. Cicéron, partagé entre le refus de la guerre civile comme danger immédiat et l'impossibilité de mener une guerre régulière, parle d'un nouveau type de guerre ${ }^{19}$ où un ennemi public se confronte à un État, dans une guerre aux fausses apparences. Cette fiction est un instrument dans les mains d'Antoine mais aussi pour le Sénat... Alors que l'état de guerre civile est évident, Cicéron compacte l'expression de guerre civile avec un verbe généralement employé pour déclarer une guerre régulière : «bellum nefarium illatum rei publicae» ("guerre néfaste menée contre la république », Phil. VI, I, 2). Une question cruciale dans les débats du Sénat porte sur la décision ou non d'envoyer des délégués à Antoine; Cicéron s'y oppose car ce serait lui reconnaitre une belligérance, même si rien de comparable au droit international n'existe. Cicéron confond sciemment le mode juridique et le mode politique en disant que « c'est moins une députation qu'une déclaration de guerre [denuntiatio belli], s'il refuse d'obéir; car on a pris le même décret que si on envoyait des délégués à Hannibal » (Phil. VI, II, 4) ${ }^{20}$. Cet envoi est une déclaration de guerre qui ne s'avoue pas, la reconnaissance de belligérance ne reconnaitrait qu'un faux ennemi régulier. En fait la guerre est déclarée depuis longtemps. Il faut affronter le danger mais refuser à Antoine le statut honorable d'adversarius ; pour les besoins de l'argument Antoine redevient provisoirement inimicus ${ }^{21}$. Seule Rome doit avoir l'initiative de la guerre, mener une guerre contre Antoine sans admettre la réciprocité avec l'ennemi ${ }^{22}$; il eût été impossible,

19. Phil. VIII, III, 9 : c'est dans la fameuse distinction entre bellum et tumultus que Cicéron estime que Rome est « in hac tam dispari ratione belli».

20. «Quamquam [...] non est illa legatio, at denuntiatio belli, nisi parverit : ita enim est decretum ut si legati ad Hannibalem mitterentur. »

21. Le terme est employé comme l'opposé exact de l'amicus, que doit être tout citoyen romain, voir Phil. V, I, 3-4. 
dans le De officiis, de soutenir cette proposition révélatrice d'une conduite non conforme à la justice dans la guerre. Les Philippiques sont bien l'envers du De officiis. Rome ne peut mener qu'une guerre convenable, Antoine commence une guerre honteuse ; Cicéron rétablit les termes de l'alternative qui sont aussi la marque d'une corrélation réciproque : "aut honesta pax aut bellum necessarium» ( "ou bien une paix honnête ou bien une guerre nécessaire », Phil. V, I, 3 ; voir aussi II, 5) est sans doute le rappel qu'il ne faut à aucun prix accepter une paix «pleine de pièges » (Off., I, XI, 34 et 7489).

La figure positive de l'ennemi régulier comme contrepoint à la figure d'Antoine est Hannibal. Le passage est remarquable car dans la littérature latine Hannibal incarne la peur pour Rome menacée là aussi d'extinction, il est le type de l'ennemi déloyal et acharné. Or, pour rabaisser Antoine, Cicéron déroge à la tradition et au lieu commun pour faire d'Hannibal l'ennemi digne de réciprocité, contre lequel la guerre est conforme au jus belli (« droit de la guerre ») décrit dans le De officiis. Le balancement entre Hannibal, redoutable mais promu ennemi authentique, régulier, sans dissimulation, et Antoine, par comparaison ennemi indigne, criminel et sacrilège, devait avoir sur les auditeurs un effet de stupéfaction : Antoine est pire qu'Hannibal.

Ainsi donc, Hannibal fut un ennemi et c'est un citoyen qu'Antoine ? Quels sont les actes d'hostilité, accomplis par le premier, que l'autre n'ait accomplis ou n'accomplisse, ou ne prépare, ou ne médite ? Partout où sont passés les deux Antoine, ce ne furent que ravages, destructions, meurtres, pillages, excès dont s'abstenait Hannibal. [...] C'est à cet homme, grands dieux, qu'on décide d'envoyer des délégués ! Ces gens-là connaissent-ils la constitution de l'État, le droit de la guerre, les exemples des aïeux (Phil. V, IX, 25) ${ }^{23}$ ?

C'est le contraire de ce que soutenait Cicéron l'année précédente dans le Laelius où Hannibal, comparé à Pyrrhus, se signalait par sa déloyauté24. Hannibal est ici un véritable ennemi, prêt à détruire le peuple romain mais aussi juridiquement désigné comme tel et se conformant au droit de la guerre formelle ; Rome et Carthage étaient hostes réciproques. Il n'y a aucune res-

22. Phil. XII, VII, 17 : «Moi, je l'ai toujours appelé ennemi [hostem], quand les autres l'appelaient adversaire [adversarium], et toujours j'ai parlé de guerre [bellum] quand les autres parlaient d'alerte [tumultum]. »

23. «Ergo Hannibal hostis, civis Antonius? Quid ille fecit hostiliter, quod his non aut fecerit aut faciat aut moliatur et cogitet? Totum iter Antoniorum quid habuit nisi depopulationes, vastationes, caedes, rapinas? quas non faciebat Hannibal. [...] Ad hunc, di boni, legatos mitti placet! Norunt isti homines formam rei publicae, iura belli, exempla maiorum?»

24. Laelius, VIII, 28. Voir aussi Off., I, 38. 
semblance entre les deux figures, Antoine est un citoyen impie, il est aussi un ennemi faux :

La seconde guerre punique, qu'Hannibal mena contre nos ancêtres, eut pour cause l'attaque contre Sagonte. C'est à bon droit [recte] qu'on lui a envoyé des délégués : on les envoyait à un Carthaginois, on les envoyait pour défendre des ennemis d'Hannibal, nos alliés. Qu'y a-t-il de semblable enfin? Nous, nous envoyons une députation à un citoyen, pour lui interdire d'investir, d'attaquer un général, une armée, une colonie du peuple romain, de ravager les campagnes, de se conduire en ennemi [... ne sit hostis] (Phil. V, X, 27) 25 .

Cicéron dépeint un monde à l'envers, où un citoyen a une conduite plus blâmable que le pire ennemi de Rome, où l'on doit empêcher un Romain d'investir sa propre ville, où un orateur doit faire l'éloge du Punique pour défaire un consul. Par caractérisations successives, il parvient à construire une détermination complexe de la guerre civile sacrilège, qui s'élabore en creux par la figure honnie d'Antoine. L'ennemi impossible est en fait une bête sauvage et monstrueuse, "belva taeterrima", qui inaugure une guerre horrible et misérable, «taetro miseroque bello» (Phil. V, XIV, 39).

\section{Antoine, monstre politique}

La contradiction inhérente à la guerre civile est rejetée sur la figure de l'ennemi-concitoyen. Antoine, dès lors, est un monstre ; sa conduite incompréhensible, entrainant la cité à se détruire elle-même, est une anomalie politique $^{26}$.

Le refus par Antoine de son identité partagée avec les autres citoyens, selon Cicéron, entraine son aliénation par rapport à la communauté. Les termes du danger impliquent qu'il faut conjurer l'aliénation de la communauté elle-même. C'est pourquoi Antoine est dénoncé comme un faux citoyen. De même que la guerre civile est un faux-semblant de guerre étrangère, de même la ressemblance du monstre Antoine avec un citoyen est désormais une fausse ressemblance. Notons que la ressemblance, l'alter idem («l'autre

25. «Belli Punici secundi, quod contra maiores nostros Hannibal gessit, causa fuit Sagunti oppugnatio. Recte ad eum legati missi : mittebantur ad Poenum, mittebantur pro Hannibalis hostilibus, nostris sociis. Quid simile tandem? nos ad civem mittimus, ne imperatorem populi Romani, ne exercitum, ne coloniam circumsedeat, ne oppugnet, ne agros depopuletur, ne sit hostis?»

26. La lecture tardive de l'article de C. Lévy, 1999, « Rhétorique et philosophie : la monstruosité politique chez Cicéron », Revue des études latines, tome 76, Paris, les Belles Lettres, p. 139-157, m'a malheureusement empêchée d'en bénéficier ici. 
identique »), est au fondement de toute amitié ${ }^{27}$. Pour le démasquer et le désigner à nouveau, Cicéron montre la vraie nature politique de l'ennemi intérieur en en faisant une bête sauvage qui, dans le vocabulaire, se rapproche du monstre. "Quant à M. Antoine, qui pourrait le considérer comme un citoyen et non comme le plus odieux [taeterrimum] et le plus cruel des ennemis?» (Phil. V, VIII, 21). L'adjectif taeter, récurrent dans les Philippiques ${ }^{28}$, fait référence à quelque chose d'horrible, de hideux, de repoussant. Antoine aime le massacre, menace les sénateurs, se poste aux portes de Rome, trompe ses soldats, égorge les centurions fidèles à leur patrie, vole les riches, tue les pauvres, se vautre dans les beuveries et, plus grave, se parjure. Le monstre est repoussant parce qu'il est sauvage, il ne peut donc que mener une guerre de bête sauvage ${ }^{29}$ et contre nature. Ce qui est bête sauvage, transposé au sein de l'entité politique, devient monstre politique. Ce sens de monstrueux est inclus dans l'adjectif taeter qui accompagne souvent le terme belva; Cicéron va jusqu'à user du terme monstrum, qui généralement n'appartient pas au registre politique. L'aspect inconcevable de l'ennemi intérieur est rendu par le redoublement de monstrum par prodigium ${ }^{30}$.

C'est donc à une apparence de citoyen que Rome a affaire, à une «species civis ». La fausse ressemblance est la marque de la séparation d'avec le peuple romain. À propos du meurtre de Trébonius, gouverneur d'Asie tué par Dolabella, récent allié d'Antoine, Cicéron écrit qu'il «a succombé, imprudent s'il avait affaire à un ennemi déclaré [aperte hostis], malheureux si c'était encore à une apparence de citoyen [civis speciem] » (Phil. XI, II, 5). L'apparence de citoyen résout en partie le problème lié à l'hostis, ennemi régulier mais aussi ennemi public; la civis species est l'hostis qui ne se découvre pas $^{31}$. Ce concept péjoratif permet de pallier l'insuffisance de la détermination de l'ennemi intérieur et celle de la guerre civile comme appa-

27. Laelius, IV, 15 ; XIV, 50 ; XXI, 80.

28. Pour taeter appliqué à Antoine, ainsi que belva: Phil. III, XI, 28 ; Phil. IV, V, 12 (« immani taetraque belva »); Phil. VI, III, 7 (" importunissima belva »); Phil. VII, IX, 27 ( taetram et pestiferam belvam »); Phil. VIII, IV, 13 ; Phil. X, X, 22 (" quid illa taetrius belva, quid immanius?»); Phil. XII, XI, 26 ("taeterrima belva »); Phil. XIII, III, 5 ( immanis belva »); Phil. XIII, X, 22 («importunissima belva »).

29. Selon Off., I, XI, 34, il y a deux sortes de guerre. Le conflit se règle soit par la violence et il est propre aux bêtes sauvages, soit par le débat et est propre aux hommes ; la guerre conforme à la justice est déduite de ce second type de conflit.

30. Phil. XIII, XX, 49 : «Ces gens sont des monstres, des prodiges et des fléaux pour la République »; Cat. II, I, 1 : «Désormais ce monstre, ce prodige ne préparera plus au sein de la ville la destruction de la ville elle-même. »

31. On trouve la même idée du dehors honnête et de la fausse nature chez Salluste, Conjuration de Catilina, $\mathrm{X}$. 
rence de guerre étrangère. Preuve qu'il s'agit d'une élaboration générale portant sur le concept d'ennemi, Cicéron opère la même démonstration à propos de Dolabella ${ }^{32}$.

Enfin le terme de cette caractérisation d'Antoine comme ennemi plus que public, car la guerre civile est dite «plus quam civile» (« plus que civile ») $)^{33}$, est atteint avec l'exécration. Antoine est non seulement un «improbus civis » ( " citoyen malhonnête »), il est un « citoyen exécrable, né pour le malheur de la République » («detestabilem civem rei publicae natum », Phil. XIII, I, 1 ; aussi Phil. VI, VI, 16). Antoine déroge à la destination du Romain à sa naissance dont le De officiis fait un principe de la nature politique : " une part de notre existence est revendiquée par la patrie, une part par nos amis » («non nobis solum nati sumus ortusque nostri partem patria vindicat, partem amici», Off., I, VII, 22).

Dans le sens où c'est Antoine qui se désigne en premier lieu comme ennemi de ses concitoyens et où cette première déclaration est réassumée, selon Cicéron, par le Sénat et le peuple qui le déclarent officiellement ennemi public indigne, la mise au ban devient exécration; la guerre civile, ici fausse guerre étrangère, exclut toute réciprocité et toute légitimité formelle. Pour accomplir le dessein de Cicéron qui veut condamner Antoine afin d'éviter la condamnation à mort de la République, il faut rendre l'ennemi apatride.

Faire sortir le monstre de la cité où il n'a plus de place, le séparer définitivement de son origine et de son apparence frauduleuse, c'est conjurer la contradiction de l'" hostis togatus » («l'ennemi revêtu de la toge »), développé immédiatement en "hostis rei publicae» (Phil. II, XXI, 51); à toute horreur il faut une formule conjuratoire. Pour dépasser les confusions entre la langue latine et ce que le français en a conservé, nous sommes contraints aux néologismes: Cicéron, après avoir hostilisé Antoine, veut le rendre étranger, l'extranéiser.

L'entrelacs des différentes caractérisations de l'ennemi Antoine n'est jamais contradictoire; celles-ci s'ajustent l'une à l'autre et se précisent mutuellement. Cicéron, au cours du texte, remplace avec insistance «hostis publicus» par «hostis externus» (« ennemi extérieur», Phil. XIII, III, 5). Cette dernière expression, loin d'être redondante, garde en fait le souvenir de l'adjectif publicus et lui substitue externus, comme pour confirmer la transformation conceptuelle du terme ennemi. Dans le passage, Cicéron emploie un irréel du présent qui montre le conflit du souhait contraire à la réalité pré-

32. Phil. XI, I, 3.

33. L'expression bellum plus quam civile se trouve par exemple chez Lucain, I, 1 ; plus quam bellum, chez Florus, II, 13, 4. 
sente - Antoine ne peut être complètement étranger - et de l'ancien potentiel du passé où «la condition est supposée possible par un report dans le $\operatorname{passé}^{34} \gg-$ Antoine, ancien citoyen, n'est pas seulement un ennemi public ${ }^{35}$. D'où la démonstration rétrospective, dans le discours, de l'origine pervertie et dévoyée d'Antoine.

Il y a un lien essentiel entre l'origine trahie et le monstre politique, entre le dévoiement de l'idée de guerre et la guerre interne contre laquelle, hélas, on ne peut élever que de l'irréel du présent. Il faut donc que Cicéron arrache Antoine à son origine, sinon c'est Rome qui deviendra étrangère à ellemême. La seule réponse susceptible d'être efficace consiste à renverser (fictivement, dans l'irréel du présent) l'hostilité, c'est-à-dire à rendre Antoine étranger à Rome. En effet, la guerre civile ne voit sa contradiction détruite, par rapport à la guerre juste, que par une sorte de postulat selon lequel «praesertim cum omnino nulla causa iusta cuiquam esse possit contra patriam arma capiendi» ("personne n'a jamais eu de raison légitime pour prendre les armes contre la patrie » Phil. II, XXII, 53).

On comprend dès lors le sens de l'image d'Antoine privé de maison qui pouvait paraitre d'abord anodine. La mise au ban, l'exécration n'étaient que les autres noms d'un évènement survenu à Antoine à la mauvaise nature : il n'est plus chez lui nulle part. Les Philippiques se développent en creux, à rebours du De officiis et du De republica où la demeure est une métaphore de la Ville dans laquelle s'exercent les liens de l'amicitia. Dès lors qu'il s'élève contre «les dieux, les pères, contre les autels et les foyers, contre la patrie » (Phil. II, XXIX, 72), Antoine n'a plus ni foi ni loi, ni feu ni lieu, il est sans demeure, il ne possède sa maison qu'en commun avec ses créditeurs :

Mais quelle maison ? chacun à ce moment avait la sienne, mais la tienne n'était nulle part. Mais que parlé-je de maison? y avait-il sur terre un lieu à toi, où tu puisses poser le pied, si ce n'est le seul domaine de Misène, que tu possédais en commandite, comme les publicains possèdent Sisapon (Phil. II, XIX, 48) ${ }^{36}$ ?

34. A. Ernout et F. Thomas, 1953, 1994, Syntaxe latine, Paris, Klincksieck, p. 239.

35. "Hostis si esset externus, id ipsum vix, talibus factis, sed posset aliquo modo : maria, montes, regionum magnitudines interessent ; odisses eum quem non videres. » En français : «Si c'était un ennemi de l'extérieur, ce serait même difficile après de tels actes, mais on le pourrait de quelque manière : des mers, des monts, des étendues de pays s'intercaleraient, on haïrait un homme qu'on ne verrait pas. »

36. "Quae autem domus? suam enim quisque domum tum obtinebant nec erat usquam tua. Domum dico; quid erat in terris ubi in tuo pedem poneres praeter unum Misenum, quod cum sociis tamquam Sisaponem tenebas?» 
L'ennemi intérieur refuse, avec la demeure, l'appartenance au groupe d'amis et son origine aussi bien naturelle que politique; il renie la patrie et met la Ville sens dessus dessous. En cela les Philippiques sont l'envers et le miroir des traités philosophiques Laelius et De officiis ; les apparences prennent le dessus, la droite devient gauche, l'ami, ennemi, le bellum, bellum civile. Dans la bouche de Cicéron, après les mutations conceptuelles par ajustements et associations, Antoine doit être dit non-citoyen, absence de citoyen, il n'a plus de lieu politique qui l'accueille ; Cicéron s'écrie, là aussi dans une formule conjuratoire : «Tu ne sens donc pas qu'à notre cause le monde entier est ouvert, alors que toi, en dehors de tes retranchements, tu n'as rien où mettre tes pas?» («Non igitur sentis huic causae orbem terrae patere, te extra munitiones tuas vestigium ubi imprimas non habere? », Phil. XIII, XV, 30).

Alors que la guerre civile est considérée comme le transport monstrueux de la notion de guerre au sein de l'unité politique, Cicéron concentre toute la contradiction politique, qui nait dans la violence, dans la figure de l'ennemi. Il élimine enfin le faux-semblant de l'ennemi intérieur, qui a l'apparence du citoyen, en expulsant hors de sa maison celui qui n'a plus d'appartenance politique cohérente. Les accusations de débauche ne sont pas là pour renchérir gratuitement sur la dévalorisation, elles sont là pour montrer qu'Antoine n'a plus que cette nature perverse pour identité. Le parricide, dans le bellum civile, devient nécessairement apatride. L'hostilisation inachevée d'Antoine devient une extranéisation hors de toute sphère politique. Par ce mouvement Cicéron entend donc restaurer l'unité du peuple et sauver l'identité de Rome.

L'harmonie disparait dès lors que les parties de la sphère politique se désolidarisent dans la scission interne et la perte de ressemblance entre les citoyens. Les tentatives pour transformer l'ennemi intérieur en monstre extérieur, la guerre civile, en un mal révocable, s'avèrent infructueuses, car Cicéron, en voulant protéger la République, aboutit au constat contradictoire à ses yeux qu'elle a des citoyens qui lui sont hostiles. Ainsi les faux-semblants de la guerre civile ne peuvent être tous désamorcés. Le mal y est toujours déjà fait. La vertu de l'homme politique est toujours en retard par rapport au bouleversement et à la ruine. Antoine, nouveau nom de la stasis, sort vainqueur et la République, malgré l'art oratoire et la volonté performative de Cicéron, sera bientôt aliénée en Empire; le véritable ennemi n'était pas Antoine, mais bien Octave. 


\section{Résumé / Abstract / Compendio}

Cicéron contre Antoine : la désignation de l'ennemi dans la guerre civile

La guerre civile, dans les écrits de Cicéron, n'apparait pas dans les traités philosophiques mais constitue l'horizon des Philippiques, discours politiques de la même époque (- $44-43)$. La guerre civile relevant du non-sens politique, Cicéron en déplace l'analyse et transforme les contenus du concept d'ennemi intérieur. Antoine est hostis publicus mais aussi fauteur d'une guerre qui ne peut être extérieure que de manière fictive. Il est assimilé au monstre politique, qui doit être rejeté hors de la sphère de la civitas. Les Philippiques, à ce titre, sont l'envers des traités philosophiques ; la pensée politique prend la forme d'une rhétorique dénonçant le faux citoyen à rebours de la communauté.

Mots clés : guerre civile, ennemi (hostis publicus), monstre politique, République, Rome.

Cicero versus Anthony: naming the enemy in civil wars

In Cicero's works, civil war appears in the Philippics, the political discourses written in the period $-44-43$, rather than in the philosophical treaties. Being related to the political nonsense, civil war is treated in such a way that the concept of the enemy from within has its contents highly transformed. Anthony is not only hostis publicus but also the culprit of a war which, unless it is fiction, can hardly be an outside one. He is made comparable to the political beast who has to be rejected from the civic sphere. As such, the Philippics can be regarded as the philosophical treaties turned upside down : political thought takes the shape of a rhetoric denouncing the wrong citizen rubbing the community up the wrong way.

Key words : civil war, enemy (hostis publicus), political beast, Republic, Rome.

Cicero contra Antonio : como llamar al enemigo en la guerra civil

En los escritos de Cicero, la guerra civil no aparece en los Tratados filosóficos, pero constituye el orizonte de las Filípicas, los discursos políticos del mismo periodo (- 44 -43). La guerra civil participando del no-sentido político, Cicero desplaza el análisis correspondiente y transforma los contenidos del concepto de enemigo interior. Antonio es hostis publicus, pero también el iniciador de una guerra que sólo puede ser de una manera ficticia, exterior. Está asimilado al mónstruo político que tiene que ser rechazado fuera de la esfera de la civitas. Las Filípicas son la otra cara de los tratados filosóficos ; el pensamiento político toma la forma de una retórica que denuncia al falso ciudadano opuesto a la comunidad.

Palabras claves: guerra civil, enemigo (hostis publicus), mónstruo politico, República, Roma. 